\title{
La literatura y el cine: una historia de relaciones ${ }^{1}$
}

\author{
Gabriel Baltodano Román ${ }^{2}$ \\ Universidad Nacional, Costa Rica
}

\section{Resumen}

La literatura y el cine se relacionan en cuatro aspectos básicos: la literatura determina, en sus orígenes, la naturaleza de los filmes, sus motivos y estrategias; la literatura y el cine son formas narrativas, por lo que comparten estructuras míticas, populares y de relato; ambos se vinculan mediante el problema de la adaptación; y el cine ejerce una influencia estética en las obras literarias y en el concepto tradicional de literatura. Este artículo examina estos vínculos desde una perspectiva conceptual e histórica.

\section{Abstract}

Literature and cinema are related in four main aspects: in its origins literature determines the nature of films; literature and motion pictures are narratives, and share mythical, popular and narrative structures; both are linked because of the issue of adaptation; and movies influence literary works and the traditional concept of literature. This article examines these relationships from a conceptual and historic perspective.

Palabras clave: literatura y cine, literatura comparada, historia del cine Keywords: literature and motion pictures, comparative literature, history of cinema

Recibido: 10 de julio de 2009; aceptado: 29 de julio de 2009.

Correo electrónico: jgbaltodanor@ costarricense.cr 
«Un polvo luminoso se proyecta y danza sobre una pantalla; nuestras miradas se empapan de él; toma cuerpo y vida, nos arrastra a una aventura errante; franqueamos el tiempo y el espacio, hasta que una música solemne disuelve las sombras sobre la tela, que vuelve a ser blanca».

Edgar Morin, El cine o el hombre imaginario

La historia de las relaciones entre la literatura y el cine supone una compleja y conflictiva trama; poco frecuentes son los casos en que dos formas expresivas han establecido tantos intercambios, a la vez que suscitado tantos prejuicios e incomprensiones. El estudio del contacto literatura-cine despliega una variedad de aspectos por tratar: la influencia de la literatura en el cine, la influencia del cine en la literatura, la intertextualidad y la iluminación recíproca entre artes, el lugar de la institución crítica y la literatura comparada en estas reflexiones, el concepto de literatura artística, el ciclo del consumo y sus receptores, el fenómeno editorial, la sociología de lo simbólico y el papel del escritor como guionista prototípico ${ }^{3}$.

A pesar de la diversidad del campo de estudio, existe una línea temática dominante, habitual: se trata de la revisión de las adaptaciones cinematográficas, esto es, el análisis de la recodificación cinematográfica de textos literarios. Sobre ello hay consenso teórico; tanto los pioneros estudios formalistas como los de la semiótica contemporánea insisten en la necesidad de situar el punto básico de enlace en el aspecto narrativo.

Entre los primeros se sitúa Eikhenbaum ${ }^{4}$, quien advierte que todo filme se extiende en el tiempo; por ende, el lenguaje cinematográfico, aunque basado aparentemente en la imagen, no está disociado de lo verbal. En la medida que el cine no se reduce a la mera

3 Carmen Peña-Ardid, Literatura y cine. Una aproximación comparativa (Madrid: Cátedra, 1992) 17.

4 Boris Eikhenbaum, «Literatura y cine» [1926] en François Albèra (comp.), Los formalistas rusos y el cine. La poética del filme (Barcelona: Paidós, 1998) 200-201. 
fotogenia y adquiere sentido merced al montaje, se convierte en una forma expresiva semántica; las relaciones entre encuadres suponen el desarrollo de un relato, de un discurso interior. Aunque la palabra no es lo principal en el cine, prevalece, primero, como recurso expresivo del director; segundo, como parte del proceso cognitivo del espectador.

La preeminencia del guión y. su componente narrativo-literario explica, de acuerdo con Tynianov ${ }^{5}$, otro precursor, la preocupación por el argumento, característica del cine de ficción. La trama literaria puede servir como punto de partida para la construcción del filme; sin embargo, debe ser recodificada, pues las leyes de desarrollo del argumento cinematográfico son específicas. Según esto, toda adaptación inicia, de acuerdo con $\mathrm{Eco}^{6}$, en el momento en que se abstrae la estructura de la trama. Los cuentos y las novelas, inspiración mayoritaria de los filmes, relatan historias; de forma semejante, las películas presentan argumentos. El cine vendría a ser pues, una «especie narrativa» más; su diferencia con la literatura radica en los medios expresivos de que se vale para desarrollar la trama ${ }^{7}$.

Es evidente que la reflexión en torno a estos problemas no se circunscribe a un modelo teórico determinado; por el contrario, nociones procedentes de distintos modelos conceptuales se complementan y funden a lo largo de unas meditaciones, cuyo entramado se acerca a la centuria. Este diálogo ha sido pródigo y polémico, nace a causa de una máquina, un artefacto que define, a las claras, una parcela amplia de la cultura moderna y contemporánea. En las siguientes páginas, se procuran ordenar y exponer cuatro de los principales vínculos entre lo literario (en particular, la narrativa) y lo cinematográfico.

Yuri Tynianov, «El guión» [1926] en Albèra, Los formalistas rusos y el cine: 188.

Umberto Eco, «Cine y literatura: la estructura de la trama» [1962] en La definición del arte (Barcelona: Martínez Roca, 1970) 194-195.

7 Ronald Solano, «Literatura con cinematografía» en María Lourdes Cortés (ed.), Luces, cámara, ¡acción! Textos de cine y televisión (San José: Editorial Universidad de Costa Rica, 2000) 143. 
Primera relación: la literatura afecta el desarrollo del cine como expresión estética

La primera función del cinematógrafo se llevó a cabo el 28 de diciembre de 1895. A partir de entonces y durante un lapso considerable, el nuevo invento se resistió a las etiquetas: máquina con alma, cinta de sueños, país suplementario, hechizo de la materia vulgar y cíclope moderno son sólo algunos de los nombres que recibió. Tal variedad de títulos sólo pudo proceder de una honda incertidumbre con respecto a las funciones y posibilidades del nuevo artefacto; más todavía, se relaciona con las inquietudes y anhelos del período anterior a su factura, pues delimita no tanto el objeto como las expectativas de la época.

Según indica Morin ${ }^{8}$, antes que los Lumière, muchos persiguieron sin éxito el descubrimiento de un mecanismo capaz de aprehender la realidad. La mayoría trabajaba en pos de instrumentos de investigación, pues se requerían «ojos objetivos» capaces de imprimir y descomponer los fenómenos de la naturaleza asociados con el movimiento. Sin embargo, y a pesar de los esfuerzos de este grupo de emprendedores, no fueron sino los hermanos franceses quienes desarrollaron el aparato. En su tiempo, Louis Lumière fue considerado el último pintor impresionista ${ }^{9}$; probablemente, esta imagen haya definido su hallazgo tanto mejor que cualquier otro concepto.

Forjados en el campo de la fotografía, los miembros de la familia Lumière se encontraban a medio camino entre el espíritu artístico y la aptitud empresarial. Alejadas de todo afán científico, sus producciones carentes de guión y montaje muestran paisajes, actividades cotidianas y costumbres «capturadas azarosamente» por la cámara. En el fondo, estos filmes participan de una lógica análoga a la del retrato o a la de las tarjetas postales, pues documentan vivencias y

8 Edgar Morin, El cine o el hombre imaginario [1956] (Barcelona: Paidós, 2001) 14.

9 Jacques Aumont, El ojo interminable (Barcelona: Paidós, 1997) 15. 
entornos. A la vez, explotan atractivos similares: basadas en el efecto emotivo funcionan como mercancías asociadas con el recuerdo, los amores y la devoción.

Entender la realidad inquieta poco a los Lumière; ellos prefieren trastocar sus límites y ampliarla; sus experimentos no se concentran en la naturaleza sino que se dirigen a la psicología humana, pues vislumbran el poder de la identificación ${ }^{10}$. Operaciones como diseccionar o medir of recen poco cuando se las compara con estimados bienes simbólicos como la presencia de lo ausente, la eternidad del momento, la metamorfosis del mundo en sueño y el paroxismo de lo real. El cinematógrafo adquiere valor merced a las proyecciones sociales depositadas en él (sustraer lo humano del tiempo, repetir lo idéntico e irreversible, dar vida a una imagen íntima de la conciencia, suprimir lo ordinario), no por sus aplicaciones inmediatas.

La fotogenia, término desarrollado por Delluc ${ }^{11}$ tras dos decenios de proyecciones, supone la cumbre de este tipo de pensamiento. En esencia, remite al aspecto poético adquirido por los seres y cosas cuando se los muestra en imágenes, a la belleza de lo cotidiano apresada por el cinematógrafo. La fotogenia delimitaba la «inefable quintaesencia» ${ }^{12}$ que da lugar a una nueva manifestación artística, marcaba la frontera conceptual entre la máquina y la forma estética. Tan sólo un lustro después, Eikhenbaum recomendaba «distinguir dos fases en su historia: la invención del aparato, gracias al cual fue posible reproducir el movimiento en la pantalla, y la utilización de este aparato para transformar la película en filme» ${ }^{13}$.

Al respecto, es fundamental la participación de Georges Méliès (1861-1938), quien interesado en el mundo del espectáculo y motivado

$\overline{10}$ Morin caracteriza la identificación como «participaciones afectivas» generadas por el encanto de la imagen y lo imaginario, reinos donde se recrean las aspiraciones y necesidades humanas $(2001$ : 92). Desde este punto de vista. supone una faceta más de la mentalidad mítica. Ver también Christian Metz. El significante imaginario. Psicoanálisis y cine (Barcelona: Paidós, 2001) 23-24. Louis Delluc, Photogénie (París: De Brunhoff, 1920).

Robert Stam, Teorías del cine. Una introducción (Barcelona: Paidós, 2001) 50.

Boris Eikhenbaum, «Problemas de cine-estilística» [1926] en Albèra, Los formalistas rusos y el cine: 45 . 
por su faceta de comerciante, halló en el cinematógrafo el principio de un entretenimiento. En tanto los hermanos Lumière se abocaban a recoger «vistas» de lugares lejanos, él decidió filmar breves representaciones de carácter teatral, en las que incorporaba actores, vestuarios y decorados. Entre 1896 y 1914, filmó más de quinientas películas; en éstas, utilizó trucos fotográficos y rudimentarios montajes, a partir de los cuales se erigen luego los medios del cine ${ }^{14}$.

Además, Méliès alteró la naturaleza de los contenidos proyectados; dispuesto a deleitar al público, compró el teatro del desaparecido mago Robert Houdin con el objetivo de exhibir ficciones y suministrar quimeras: las prefería por encima de la hostil realidad. El referente de estos filmes no remite al mundo adyacente sino a la imaginación y la utopía; sus temáticas lo ale jan de la estampa, para aproximarlo al viaje hacia lo maravilloso y fantástico. Todo viaje responde a un relato. Por estas razones poéticas, y por otra no estética, Méliès acerca el cine a los ámbitos del teatro y la literatura, los dos grandes discursos artísticos fundados en la fabulación y la trama, tal y como se los concebía hacia finales del siglo xIX e inicios del xx.

La razón no estética se vincula con algunos de los asuntos tratados en este apartado. Epstein describía al cine como «hermafrodita de ciencia y arte» ${ }^{15}$. Seguramente, esta fórmula sea una de las más bondadosas enunciadas en aquel entonces; en verdad, existían severas resistencias con respecto al nuevo medio. Por involucrar en el proceso un sistema mecánico de reproducción, prevalecían las dudas; algunos sectores intelectuales consideraban al cine una burda imprenta de la escena teatral, cuando no pintura venida a menos o literatura convertida en tebeo.

La tesis del mimetismo se aunaba a otros prejuicios. En una cultura organizada en torno a la palabra, la imagen es considerada un método de comunicación primitivo, pues carece de abstracción. Se

\footnotetext{
14 Georges Sadoul, Historia general del cine, tomo II (Madrid: Siglo XXI, 1972) 164.

15 Jean Epstein, Escritos sobre cine, tomo I (Madrid: Fundamentos, 1982) 16.
} 
adopta, por lo general, la falacia de que el ícono, por guardar semejanza con lo significado, reviste menor convencionalismo, es decir, posee una limitada capacidad de semiosis. Surge entonces la certeza de hallarse frente a un código débil ${ }^{16}$. Además, se la entiende como una herramienta cognitiva de escasa valía. Por todo esto, se relega al cine a los márgenes de la actividad intelectual, donde sólo sirve para esparcimiento o consumo.

En tales circunstancias, los cineastas, más que el cine, procuran una nueva valoración de su quehacer; la búsqueda de prestigio los dirige hacia las manifestaciones artísticas consagradas; en particular, hacia la literatura. La influencia de los cuentos, las novelas y las piezas dramáticas entre los realizadores del cine resulta notable. Si se piensa en el cine como el espectáculo que cuenta historias ficticias a través de una mirada subjetiva, se comprende cuánto pesó lo literario en su determinación. A claras, se podría afirmar que la primera relación entre literatura y cine es de carácter histórico y se refiere a la intervención de la primera en el nacimiento y destino del otro. Las películas de Méliès contaban pequeñas historias, pero el cine debía demostrar que podía elaborar relatos complejos. Para poder ser reconocido como arte, los creadores desarrollaron sus capacidades narrativas; al hacerlo, delimitaban los contornos de la disciplina y educaban al público en una vía.

\section{Segunda relación: el cine y la literatura comparten la estructura de la trama}

En múltiples ocasiones, ver una película equivale a escuchar una historia. Muchos filmes cuentan alguna aventura o suceso, es

\footnotetext{
16 En Semiótica y filosofía del lenguaje (Barcelona: Lumen. 2000) 57-58, Umberto Eco comenta la manera en que los signos son catalogados por la sociedad; en su opinión, las comunidades jerarquizan no sólo los discursos sino los tipos de signos y los códigos, de modo tal que algunos alcanzan mayor prestigio y otros son desplazados hacia la perif eria. No se trata de sus posibilidades intrínsecas sino del funcionamiento que se les otorga.
} 
decir, desarrollan una trama. Sin llegar a afirmar que todo el cine narra, resulta conveniente señalar esta tendencia, pues ocupa un lugar central. Se ha explicado cómo esta primacía del relato surge a causa de unas circunstancias fortuitas; atañe explicar también que obedece a una predisposición. En el cine, las imágenes adquieren carácter figurativo y movimiento. Estas cualidades les otorgan los recursos necesarios para transmitir historias.

La representación icónica muestra el objeto y sugiere algo a propósito de éste. La imagen no sólo remite a una realidad concreta sino que estimula la red de valores y simbolismos depositados en ésta por la sociedad; así, el fotograma de un arma alude a la violencia, el enf rentamiento y la criminalidad. En estos términos, incluso los trazos de una pintura rupestre contienen un relato; la lanza empuñada por la figura humana cuenta una hazaña memorable: el acto de cazar, el triunfo sobre la bestia, la supervivencia, el poder obtenido mediante la memoria y la identidad. Con cada imagen germina una historia en el espectador, afirma Barthes ${ }^{17}$.

La imagen en movimiento provoca la entelequia de continuidad y transformación perpetua a través de muchos estados. Mediante el montaje, lo filmado adquiere duración y, por tanto, devenir; no es un instante aislado sino un proceso, un desarrollo ${ }^{18}$. Deleuze arguye que el movimiento es una traslación en el espacio; cuando la hay, ocurre un cambio cualitativo. En consecuencia, el efecto del discurso filmico, su sentido, se asume como historia; los objetos retratados —en su mayoría, seres - se convierten en personajes; las escenas, en acciones o acontecimientos concatenados, progresivos ${ }^{19}$.

Además del elemento figurativo y del movimiento, un tercer principio que concurre en la narración fílmica y la hace posible es el modelo de representación. Lo constituyen un complejo entramado de

Roland Barthes, Lección inaugural (México: Siglo XXI, 1995) 143.

Jacques Aumont y otros, Estética del cine (Barcelona: Paidós, 1996) 90.

Gilles Deleuze, La imagen-movimiento. Estudios sobre cine I (Barcelona: Paidós, 1994) 22. 
convenciones que sirven como base a las expresiones audiovisuales, los preceptos formulados a lo largo de la historia del cine, aprendidos o asimilados por los creadores como una suerte de alfabeto, «lenguaje» ${ }^{20}$ o gramática del filme. El modelo de representación no procede de la imagen misma, sino de los usos concretos de los cineastas; D. W. Griffith (1875-1948) y S. M. Eisenstein (1898-1948) modelan sus orígenes. En sentido estricto, el modelo hace factible la continuidad e intelección de un relato, aunque no lo ocasiona ${ }^{21}$.

El cine dispone de imágenes con movimiento y valor figurativo y de códigos precisos para contar. Sin embargo, un relato es algo más, implica un mundo representado y unos medios para representarlo. Lo narrado incluye a los personajes, los acontecimientos enlazados, los espacios y la temporalidad; la narración, el enunciador, el destinatario y los mecanismos. Como comenta Cortés ${ }^{22}$, el relato en bruto (el mundo representado) puede ser contado mediante diferentes dispositivos de representación; así, por citar un caso, el mito de Orfeo se comunica por medio de la oralidad, la escritura literaria, el teatro, la ópera, la danza y el cine.

La semejanza de las estructuras homologa al cine con la literatura; ambas funcionan como medios para narrar. Pareciera que el acto de contar las trasciende, pues se sitúa en el origen de sus expresiones; no obstante, contar nunca supone una actividad vacía, autónoma; se narra siempre en virtud de un procedimiento. Queda claro que la novela, el cuento, la crónica y el filme desembocan en la acción, son artes de acción, géneros narrativos. Eco establece una base general: el avance de una serie de hechos; no importa si lo literario parte de la

20 A pesar del empleo indiscriminado de este término, el cine no es un lenguaje sino un denso ensamble semiótico, en el que intervienen diferentes códigos y clases de signos. Ver luri M. Lotman, «El lugar del arte cinematográfico en el mecanismo de la cultura», La semioṣfera III. Semiótica de las artes y de la cultura (Madrid: Cátedra, 2000) 132.

21 Juan Miguel Company, El trazo de la letra en la imagen. Texto literario y texto fílmico (Madrid: Cátedra, 1987) 42.

22 María Lourdes Cortés, Amor y traición. Cine y literatura en América Latina (San José: Editorial Universidad de Costa Rica, 1999) 33. 
palabra para enunciar «sucede esto y luego aquello», y el cine muestra imágenes en las que ocurre esto más esto más esto ${ }^{23}$.

Esta similitud permitió a los cineastas llevar obras literarias a la pantalla, pues bastaba, en principio, con extrapolar los acontecimientos y establecer correspondencias estéticas ${ }^{24}$. Con el tiempo, se descubre cuánto más complejo es el proceso, pues el cine cumple con funciones particulares. La aprehensión sensorial e iconográfica de los mundos imaginados por la literatura da lugar a polémicas respecto de sus capacidades analítica y persuasiva ${ }^{25}$; en el seno de la labor, obliga a meditar acerca del papel de los guionistas. La reescritura cinematográfica no sólo conduce a traducir entre tipos de signos, sino que demanda un nuevo ordenamiento de las acciones dramáticas. Asimismo, plantea incógnitas sobre la aptitud del medio audiovisual para cifrar el estilo de un escritor o una tendencia.

\section{Tercera relación: el problema de la adaptación}

La creación cinematográfica supone una experiencia inédita, pues no se asemeja a ninguna forma anterior; sétimo arte la llama Canudo ${ }^{26}$ porque deviene en síntesis moderna de las expresiones estéticas: es la última y más reciente. A causa de esto, goza de libertades excepcionales; no cuenta con tradición y, sin embargo, todo acervo le pertenece. Al lado de la música, el teatro y la plástica, el cine crece y se legitima; no obstante, el vínculo con el mundo de las letras es particularmente intenso, pues de éste proceden, mayoritariamente, sus recursos y prestigio.

Los recursos procedentes de la literatura son variados, por lo que conviene clasificarlos en tres tipos: el primero incluye los contenidos (tramas, personajes y motivos); el segundo, los agentes (autores,

\footnotetext{
23 Umberto Eco, La definición del arte (Barcelona: Martínez Roca, 1970) 196-197.

24 Jean Mitry, Estética y psicología del cine (México: Siglo XXI, 1986) 424.

25 Jorge Rojas Bez, «Serie de ensayos sobre cine», Revista Comunicación, IX, 1 (1996) 86.

26 Riccioto Canudo, L'Usine aux images [1927] (París: Seguier-Arte, 1995) 52.
} 
guionistas y críticos) y el tercero, los mecanismos expresivos. Cada categoría participa en una de las variantes del problema de la adaptación: los contenidos inspiran y ofrecen modelos, los agentes aportan reputación y contribuyen en los procesos de escritura y lectura; y los mecanismos imponen procesos de búsqueda de efectos estéticos análogos.

Desde la perspectiva del cine, la literatura constituye una auténtica enciclopedia; ávidos de historias que contar, los directores, guionistas y empresarios han acudido a sus páginas en busca de figuras, tópicos e incluso argumentos; el fenómeno es tan antiguo como el cine mismo; más todavía — se explicó en un apartado anterior-, lo determina. Méliès, por ejemplo, se apoyó en algunas obras de Herbert Georges Wells (1866-1946) y Julio Verne (1828-1905) para crear sus filmes; al hacerlo, dio lugar a las primeras adaptaciones. ¿Qué halló en las letras? Dotado de una inventiva extraordinaria, de seguro no perseguía ideas.

La primera época del cine se caracteriza por una paradoja: creado por intelectuales y sensibles, se lo confina a divertimento de simples e iletrados. El ansia de reivindicación conduce hacia las obras literarias; sin embargo, no se trata de dependencia sino de arrobamiento. McLuhan planteó que a la invención de una nueva tecnología sigue siempre un periodo de perplejidad ${ }^{27}$. Formados en una sociedad logocéntrica y bibliófila, los pioneros como Méliès están incapacitados para comprender la autonomía del mundo cinematográfico ${ }^{28}$; por el momento, sortean los malos juicios y ganan auditorio mediante el regreso a lo conocido.

Sin embargo, el fenómeno no concluyó una vez superado el arrobamiento; mucho del cine que se exhibe en la actualidad se genera a partir de materiales preexistentes; en la mayoría de las ocasiones, se trata de relatos literarios, algunos auténticos clásicos o éxitos de

Marshall McLuhan, La galaxia Gutenberg. Génesis del homo typographicus [1967] (Madrid: Aguilar, 1972) 380-381.

28 Resulta interesante cómo, décadas después, emerge el tópico de la invasión. Kracauer, Chiarini y Zavattini condenan la orientación literaria del cine, a la vez que abogan por la emancipación de la imagen. 
ventas, otros por completo desconocidos. Acudir a textos célebres no esconde de por sí una intención comercial, las editoriales también lo hacen: ora para vender, ora por exigencia de los lectores, ora por su deseo de preservar el vigor de unas manifestaciones consideradas canónicas $^{29}$. No existe entonces dependencia, sino un uso llano. En el caso de las obras sin renombre parece más evidente, sin por esto ser privativa, la exploración artística.

Solano utiliza términos con sentido metafórico para distinguir entre dos corrientes; él habla de parasitismo y mutualismo ${ }^{30}$. En una, la industria del cine usurpa el capital simbólico del literato, su imaginación y estilo; en la otra, la literatura motiva nuevas narraciones y experiencias, sugiere, provoca. Estas dos actitudes desembocan en dos maneras de emprender el oficio de adaptador: o se reproduce e imita o se actúa como un creador, es decir, se dialoga, se impone un nuevo orden a la pieza literaria y se la revitaliza.

Esto es interesante si se piensa, primero, en el auditorio, y segundo, en el concepto mismo de adaptación. En una gran proporción, el público ha sido educado en la necesidad de establecer comparaciones entre la obra literaria y el filme; en el fondo, valoran la fidelidad por encima de la creatividad. Al parecer, priva la minuciosa duplicación sobre la independencia. Sin embargo, el término adaptar refiere ajuste, reacomodo; es decir, el traslado de un objeto a través de dos circunstancias diferentes, un cambio en su naturaleza ${ }^{31}$. Estas modificaciones afectan, entre otros asuntos, la extensión y complejidad de la trama. El relato literario, cuantioso en personajes y episodios, es llevado a las salas de cine en un lapso determinado por el dispositivo de la proyección $^{32}$. Antes que reducir o simplificar, se procura una síntesis.

29 Vale recordar el comportamiento del campo literario descrito por Pierre Bourdieu en Las reglas del arte (Barcelona: Anagrama, 1990).

30 Solano, 145.

31 «Modificar una obra científica, literaria, musical, etc., para que pueda difundirse entre público distinto de aquel al cual iba destinada o darle una forma diferente de la original», DRAE, $22^{\mathrm{a}}$ ed.

32 Todo filme tarda entre una y tres horas, esto constriñe. Las adaptaciones televisivas segmentan la trama en capítulos, por esto, con frecuencia, preservan su organización básica. En el cine, varía notablemente. 
Esta síntesis emerge como realidad nueva, ligada al texto literario en tanto referente; nunca existe pérdida; en rigor, hay aporte. Adaptar no es un acto moral; por tanto, no se ajusta a criterios tales como traición o lealtad. Una adaptación esconde dentro de sí, desde el primer momento, una lectura; pues todo realizador interpreta el texto literario, es decir, interviene en su significación. Al cooperar con el texto, el cineasta no sólo conoce lo comunicado, sino que lo modela a su propia medida y por medio de sus conocimientos y de su sensibilidad ${ }^{33}$.

En estos términos, lo proyectado no expresa continuidad mecánica sino réplica; lo proyectado no equivale a leer el texto de origen, se debe entender como una réplica ante éste, como un producto derivado, como diálogo entre conciencias ${ }^{34} \mathrm{y}$, a veces, entre sabios; quién no goza estética e intelectualmente las versiones de Otelo y el Quijote preparadas por Orson Welles. La adaptación implica pues arduos procesos constructivos; interpretar deriva de un vocablo latino utilizado para referirse al negociador, traductor o intermediario ${ }^{35}$. La literatura no se sitúa en un nivel superior, tan sólo provee de materia prima e iluminaciones. Parece adecuado dejar de lado los cotejos para escuchar con claridad los puntos de vista; el cine devuelve al discurso literario su papel social: provocar ideas.

\section{Cuarta relación: el cine afecta las estéticas de la literatura}

Para Eikhenbaum, el auge de las adaptaciones redefinía las fronteras del trabajo literario; incluso se preguntaba sobre los deberes del escritor para con el público: ¿una vez entregado el escrito a la im-

\footnotetext{
33

Umberto Eco, Lector in fabula (Barcelona: Lumen. 1981) 37.

Lotman describe al texto como «un complejo dispositivo que guarda variados códigos, capaz de transformar los mensajes recibidos y de generar nuevos mensa jes, un generador informacional que posee rasgos de una persona con un intelecto altamente desarrollado" (15). A causa de estas propiedades intelectuales, el texto no funciona como mediador sino como agente de diálogo y promotor del pensamiento. Ver «La semiótica de la cultura y el concepto de texto», Escritos. 9 (1993) 15 y 19. David Bordwell, El significado
} 
prenta; no será factible crear una versión para la pantalla? ${ }^{36}$ Bazin lo recomendaba; en su opinión, «la cultura en general y la literatura en particular no tienen nada que perder en esta aventura ${ }^{37}$. Estas afirmaciones, aun cuando parecen optimistas, deben ser interpretadas a partir de una convicción común entre los críticos de la época: la literatura se ha convertido en un bien apreciado por minorías. A pesar de que un alto porcentaje de los vanguardistas descalifica a los seguidores del cine por preferir géneros y estéticas pasantistas, está clara la influencia de esta expresión en grandes sectores.

Entre los artistas dedicados al teatro y la pintura, prevalece el temor; los inquieta la presunta rivalidad comercial atribuida al sétimo arte. Algunos conciben el discurso audiovisual como una nueva imprenta, que fija las puestas en escena o divulga las tramas literarias. Otros hallan en los filmes un vehículo de propaganda, que se encarga de conmover al espectador e incitarlo para que busque las formas originales, modelo de profundidad y refinamiento cultural. Los escritores también temen la disminución en las ventas editoriales; ellos no sólo contemplan el auge del cine, sino que participan de la industria.

Convertidos en maquila por Hollywood, autores como Hemingway, Faulkner, Steinbeck o Hammett descubren con desagrado la mezcla de industria y arte. En respuesta, cultivan una literatura anticinematográfica. Critican, además, la prostitución del talento, la ausencia de espacios para la individualidad creativa y el afán por of recer al público objetos de ínfimo nivel cultural. Desde entonces, la sociedad entre medio visual y literatos se define como convulsa; en algunos casos excepcionales, los escritores aprenden del cine o lo proclaman paradigma de la modernidad y el cambio.

En ambos casos, el cine injiere en el desarrollo de la estética literaria y del arte, en general. Benjamín fue el primero en percibir

\footnotetext{
36 Eikhenbaum, «Literatura y cine», 198.

37 André Bazin, «Por un cine impuro» [1958], ¿Qué es el cine? (Madrid: Rialp, 1990) 114.
} 
este fenómeno; hacia 1935, escribió una serie de fragmentos bajo el título «La obra de arte en la época de su reproductibilidad técnica». En el undécimo apartado, señala el principal atributo de lo fílmico: es la nueva y más perfecta máquina para contar; por tanto, desplaza a aquellas manifestaciones expresivas que se fundamentan en el acto de relatar historias ${ }^{38}$. La narrativa literaria se redefine a partir de este hecho; en las formas modernas, prevalece, por ejemplo, el abandono del argumento ${ }^{39}$.

Según se ve, las influencias se gestan en niveles profundos. No se trata de identificar engañosas equiparaciones literarias de artificios fílmicos, sino de reconocer cómo el discurso de la imagen en movimiento amplía los horizontes de la escritura. Entre los aportes más significativos del cine a la literatura se encuentran: los motivos de la cultura popular, el diálogo intertextual, la economía expresiva, la fragmentación y el uso reiterado de perspectivas. En su mayoría, éstos resuenan en las obras de los vanguardistas, los narradores norteamericanos de la Generación perdida, los novelistas franceses de las décadas del treinta y el cuarenta y los hispanoamericanos contemporáneos.

Las películas, sobre todo las producciones estadounidenses de serie B - melodrama, western y cine negro_, forjaron el imaginario del consumo masivo; sea mediante lo sentimental, la aventura o la violencia, estos filmes codificaron personajes, ambientes y procesos que constituyen, en la actualidad, una suerte de folclor urbano; es decir, conforman un discurso de cultura ${ }^{40}$. Este discurso es material para el escritor; el análisis del corpus referencial de la literatura moderna y contemporánea arroja interesantes evidencias al respecto; así, abundan los homenajes y las parodias de figuras e historias del cine. En lengua española, van desde Gómez de la Serna y Lorca hasta Donoso, García Márquez, Manuel Puig, Cabrera Infante, Osvaldo Soriano y Leonardo Padura.

\footnotetext{
Walter Benjamín, Discursos ininterrumpidos (Madrid: Taurus, 1973) 49.

39 Raul Torres, «La presunta futura obsolescencia del cine», Escena, 13 (1985) 25.

40 Alfonso Puyal, Cine y arte nuevo (Madrid: Biblioteca Nueva. 2003) 18.
} 
Más allá de las alusiones ocultas o deliberadas, importa la evidencia de la intertextualidad. De acuerdo con Kristeva, la productividad textual está determinada por lo histórico; de esta forma, en todo texto están presentes los anteriores ${ }^{41}$. Esta dinámica impone nuevos contenidos y formas a la literatura; en lugar de las mitologías arcaicas, acude con fines estéticos a las certezas del capitalismo industrial. Ese interés se relaciona con la necesidad poética de cuestionar la jerarquía axiológica de la cultura y el canon; lo literario se mueve entonces a través de un mundo considerado bajo o vulgar con el objetivo de evitar el anquilosamiento ${ }^{42}$.

Junto a los préstamos conceptuales, se sitúan las modelizaciones cinematográficas. Para evitar la duplicación de datos, los cineastas practicaron la economía expresiva desde los comienzos; la premisa parece sencilla: enunciar mucho con pocos recursos. En el campo de las letras, y tras la ruptura con las estéticas del realismo clásico, los escritores ensayaron este postulado; querían delimitar los caracteres y su entorno sin dedicar espacios extensos a los apartados descriptivos, pues entorpecían el ritmo del relato. Ansiosos por el vértigo de los acontecimientos - añoraban la velocidad del cine-, cultivaron una prosa carente de adjetivos. Asimismo, recuperaron el diálogo en tanto eje del progreso dramático; en buena medida, la mordacidad e ironía de Hemingway y Chandler se asocian con sus aficiones por el cine.

Hauser afirma que el cine es la forma más representativa de las estructuras mentales de la época reciente ${ }^{43}$; la idea de un tiempo escindido y dislocado se concreta merced al montaje. La fragmentación y el empleo de puntos de vista inusuales distinguen a los filmes de las otras clases de relato. No obstante, con el paso del tiempo, estas técnicas han migrado hacia las páginas de las novelas. Por último,

\footnotetext{
$\overline{41}$ Julia Kristeva, El texto de la novela (Barcelona: Lumen, 1974) 119.

42 Consultar el escrito de Lotman «Sobre el contenido y la estructura del concepto de literatura artística» en Semiosfera I. Semiótica de la cultura y el texto (Madrid: Cátedra, 1996) 162-181.

43 Amold Hauser, Historia social de la literatura y el arte, tomo III (Madrid: Guadarrama, 1976) 280.
} 
valga mencionar que los escritores no sólo se aproximan a los recursos y tópicos del cine para resolver sus propias inquietudes, sino que delimitan sus proyectos estéticos a partir de la distancia con lo audiovisual. Así, las novelas de autores como Joyce y Proust plantean asuntos y estrategias de difícil adaptabilidad fílmica ${ }^{44}$.

\section{Epílogo}

El estudio de las relaciones entre la literatura y el cine debe impeler hacia el análisis de los problemas sociales y las asociaciones vigentes en un ambiente y época determinados. El objetivo de estas pesquisas consiste en determinar cómo los mismos asuntos asumen formas distintas, a la vez que revelan las determinaciones profundas del sistema ${ }^{45}$. El principio de la trama y la palabra misma exceden los dominios de la novela y el cuento; debido a esto, el interés por el cine proporciona útiles conocimientos acerca de lo narrativo. Comprender la literatura supone, además del ejercicio hermenéutico, el recuento de la historia de sus efectos en la comunidad y en las demás expresiones estéticas. El cambio en las tendencias y los procedimientos de un segmento de las letras del siglo $\mathrm{xx}$ sólo se percibe cabalmente cuando se examinan las intrusiones de lo fílmico. Por estas razones, este asunto merece más investigación.

44 Perre Gimferrer, Cine y literatura (Barcelona: Planeta, 1985) 83.

45 Robert Stam, Nuevos conceptos de la teoría del cine (Barcelona: Paidós, 1999) 91. 